\title{
Revisão por pares aberta
}

\section{Open peer review}

\author{
Patrícia Pedri ${ }^{1}$, Ronaldo Ferreira Araújo ${ }^{2}$ \\ ${ }^{1}$ Universidade Federal de Alagoas (UFAL), Maceió, Alagoas, Brasil. ORCID: https://orcid.org/0000-0001-8443-337X \\ 2 Universidade Federal de Alagoas (UFAL), Maceió, Alagoas, Brasil. ORCID: https://orcid.org/ 0000-0003-0778-9561
}

Autor para correspondência/Mail to: Patrícia Pedri, patriciapedri@gmail.com

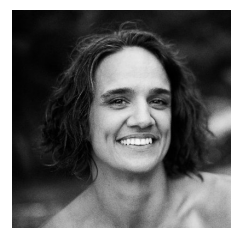

Patrícia Pedri é Bacharel em Biblioteconomia pela Universidade Federal de Alagoas (UFAL) e mestranda em Ciência da Informação (UFAL).

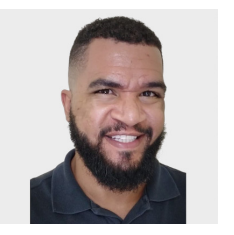

Ronaldo Ferreira Araújo é Professor do Programa de Pós-Graduação em Ciência da Informação (PPGCI/UFAL), Doutor e Mestre em Ciência da Informação em Ciência da Informação pela Universidade Federal de Minas Gerais (UFMG).

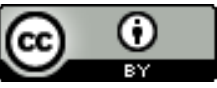

Copyright (c) 2021 Pedri \& Araújo. Todo o conteúdo da Revista (incluindo-se instruções, política editorial e modelos) está sob uma licença Creative Commons Atribuição 4.0 Internacional. Ao serem publicados por esta Revista, os artigos são de livre uso em ambientes educacionais, de pesquisa e não comerciais, com atribuição de autoria obrigatória. Mais informações em http://revistas.ufpr.br/atoz/about/submissions\#copyrightNotice.

\section{Resumo}

Patricia Pedri e o Doutor Ronaldo Ferreira Araújo apresentam o conceito, os tipos, benefícios, recomendações e o contexto de surgimento da revisão por pares aberta.

Palavras-chave: Revisão por pares aberta; Comunicação científica; Periódico científico; Política editorial.

\begin{abstract}
Patricia Pedri and Ronaldo Ferreira Araújo, PhD, presents the concept, types, benefits, recommendations and the context of the rise of open peer review.
\end{abstract} Keywords: Open peer review; Scholarly communication; Scientific Journal; Editorial Policy.

\section{Como se caracteriza a revisão por pares aberta (open peer review)?}

A revisão por pares é uma etapa anterior à publicação dos resultados das pesquisas sendo imprescindível ao sistema de comunicação científica, uma vez que por meio dela que se dá a validação destas pesquisas como científicas, independente da modalidade em que ocorre, ou seja, na revisão por pares tradicional (blind peer review) ou na revisão por pares aberta (open peer review).

Embora não haja uma definição consensual na literatura científica sobre o sistema aberto de avaliação por pares, pode-se sintetizar que a abertura do processo de revisão consiste em qualquer sistema de avaliação da comunicação científica que exponha as identidades dos atores envolvidos no processo (autores e revisores), de forma restrita ou aberta ao público e em quaisquer etapas da comunicação científica inclusive pós-publicação. Nesta definição, sob uma compreensão de abertura para além das identidades, pode-se incluir a publicação do produto da revisão, ou seja, dos pareceres junto ao artigo avaliado, sem necessariamente revelar as identidades do revisor.

\section{Em qual contexto surgiu a revisão por pares aberta?}

Se pensarmos em perspectiva histórica, os cientistas do XVII trocavam cartas e apresentavam suas pesquisas em reuniões de clubes ou sociedades científicas com a intenção de saber a opinião dos seus pares. Então, de certa forma, as primeiras avaliações de pesquisas científicas aconteceram de forma aberta entre os pesquisadores.

Contudo, ao longo dos anos, o sistema de comunicação científica consolidou uma tradição de anonimato entre revisores e autores, e nesse contexto, em 1999 o British Medical Journal (BMJ) começou a revelar a identidade dos revisores aos autores, seguido do BioMed Central em 2000 e Atmospheric Chemistry and Physics em 2001.

Então podemos afirmar que a revisão por pares aberta surge no contexto de ações mais organizadas para o acesso aberto entre o fim dos anos 1990 e início de 2000 que foram ampliadas no movimento de ciência aberta. Inclusive, esse tipo de revisão ganha centralidade em uma das escolas ou correntes interpretativas da ciência aberta, que seria a da escola das métricas, a qual se dedica a formas alternativas e mais responsivas de avaliação 
da ciência e de mensuração do uso e impacto de seus produtos.

\section{Há diferentes tipos e/ou níveis de revisão por pares aberta? Se sim, quais são eles e como podem ser descritos?}

Sim. A revisão por pares aberta não é um sistema único e pode apresentar diferentes configurações de características e entre as variações nas implementações, sendo dois fatores importantes que definem o grau de transparência: as identidades e os pareceres. Ross-Hellauer (2017) apresenta uma sistematização dessas modalidades que podem ser adotadas de forma isolada ou combinada: Identidades abertas - autores e revisores conhecem a identidade uns dos outros; Relatórios abertos - os pareceres são publicados junto ao artigo avaliado; Participação aberta - a comunidade em geral pode contribuir para o processo de revisão; Interação aberta - a discussão recíproca direta entre autores e revisores, e/ou entre revisores, é permitida e incentivada; Manuscritos abertos para pré-revisão - as pesquisas são disponibilizadas antes da publicação para comentários (preprint); Comentários abertos da versão final - análise ou comentários das publicações após a publicação; Plataformas abertas - a revisão é dissociada da publicação na medida em que é facilitada por uma entidade organizacional diferente do local de publicação.

\section{Até o momento, como é percebida a posição da comunidade científica quanto à revisão por pares aberta?}

Diferente do acesso aberto, prática da ciência aberta consolidada na América Latina, a avaliação aberta ainda causa certa desconfiança e poucos são os periódicos brasileiros que adotam esse sistema de revisão. Segundo a pesquisa de Príncipe (2018) somente 1\% das revistas indexadas no Directory of Open Access Journals (DOAJ) adotam a open peer review (OPR), e apenas 3 são brasileiras.

Em um recente estudo Wolfram, Wang, Hembree, e Park (2020) contribuem para a discussão fornecendo uma investigação mais abrangente da adoção da revisão por pares aberta em periódicos científicos e as abordagens de implementação utilizadas. Um desafio para esse tipo de estudo, segundo os autores, é que as bases de dados bibliográficas atuais não indexam sistematicamente periódicos que adotam a OPR, nem os periódicos que adotam esta modalidade de revisão afirmam claramente suas políticas sobre identidades e relatórios abertos. Usando métodos combinados, os pesquisadores identificaram 617 periódicos que publicaram pelo menos um artigo com identidades abertas ou relatórios abertos a partir de 2019 e analisaram suas implementações. Os resultados sugerem que houve uma constante na adoção de OPR desde 2001, com um crescimento mais rápido desde 2017 e que há uma diferença na adoção por áreas de conhecimento, sendo a prática mais prevalente nas disciplinas médicas e científicas $(79,9 \%)$ e em menor nas humanidades $(1,1 \%)$.

Já na comunidade científica brasileira, especificamente no campo da Ciência da Informação, a maioria dos editores entrevistados por Garcia e Targino (2017) veem vantagens na abertura do processo de revisão, especialmente por acreditarem na melhora da qualidade dos pareceres e das próprias revistas científicas; no entanto preferem a permanência da revisão tradicional às cegas.

Isso demonstra que se faz necessário mais pesquisas acerca do tema a fim de divulgar as vantagens e os desafios dessa prática para conscientizar a comunidade científica da necessidade de criar alternativas ao modelo tradicional de avaliação no sentido de tornar a comunicação científica mais transparente.

\section{Quais os benefícios e as limitações da revisão por pares aberta para a comunicação científica?}

A revisão por pares aberta engloba diferentes práticas de abertura com características que possuem benefícios e limitações também diferentes. De forma geral, a abertura do sistema de revisão proporciona mais transparência no processo de avaliação e pareceres mais construtivos, consistentes e coerentes, pois o revisor não estará mais "protegido" pelo anonimato ou, o seu parecer restrito ao autor e editor. Nesse sentido, pode até mesmo incentivar o editor a escolher revisores mais especializados no conteúdo a ser revisado para evitar questionamentos dos autores ou da comunidade.

No entanto, um parecer publicado e/ou assinado pode interferir na relação entre os pesquisadores, especialmente quando os papéis se alternam e o revisor, na posição de autor, for avaliado por alguém que recebeu outrora um parecer desfavorável.

O sistema aberto de avaliação por pares também exige procedimentos mais complexos na edição dos periódicos, como autorização específica dos atores envolvidos e infraestrutura tecnológica que facilite a revisão aberta sem prejuízos para a agilidade, ética, transparência e qualidade da comunicação científica.

Vale ressaltar que algumas desvantagens da revisão por pares aberta são comuns à revisão tradicional às cegas, haja vista que as críticas ao anonimato dos revisores apontam para a possibilidade de pareceres enviesados ou até mesmo plágio das pesquisas revisadas. Então, mais do que listar vantagens e desvantagens, talvez seja importante destacar que o grande benefício em um processo aberto de revisão por pares é que a comunidade científica 
pode identificar a ocorrência de uma conduta não-científica ou antiética por parte dos revisores, editores e autores.

6. No caso de um periódico científico adotar a revisão por pares aberta na sua política editorial, quais são algumas recomendações para os diferentes atores envolvidos (editores, avaliadores e autores)?

Editores e equipe editorial empenhados em adotar práticas condizentes com o movimento da ciência aberta precisam estar atentos às implicações que elas acarretam em outras práticas editoriais. A comunicação científica rápida, na forma de elaboração e disponibilização de manuscritos em repositórios de preprints pelos autores, por exemplo, já pressupõe que uma vez aceito para avaliação na revista, caracteriza um tipo de abertura deste processo, uma vez que as identidades dos autores serão conhecidas. Logo, revistas que passam a aceitar preprints precisam explicitar em sua política editorial que para este tipo de submissão, há prática de revisão aberta, ao menos na publicização da autoria.

Cada editor conhece o público e a comunidade da revista. Nesse caminho a ser trilhado de adesão a revisão por pares aberta é importante que o mesmo vá conhecendo a recepção desta comunidade e que vá testando os tipos de aberturas que considere ser compartilhado por seus membros. Uma boa prática é considerar em cada início de processo de avaliação, uma sondagem entre os autores e revisores sobre as possibilidades de revisão, a fim de saber quais eles mais se identificam, para assim ir desenhando o que mais se adéqua à revista. 


\section{REFERÊNCIAS}

Garcia, J. C., \& Targino, M. G. (2017). Open peer review sob a ótica de editores das revistas brasileiras da ciência da informação. In Anais do 18 encontro nacional de pesquisa em ciência da informação (enancib). Marília, SP: Universidade Estadual Paulista Júlio de Mesquita Filho. Recuperado de http://enancib.marilia.unesp.br/index.php/xviiienancib/ ENANCIB/paper/view/19.

Ross-Hellauer, T. (2017). What is open peer review? a systematic review. F1000Research, 6(588). Recuperado de https://periodicos.ufsc.br/index.php/eb/article/ view/1518-2924.2009v14n28p73.

Wolfram, D., Wang, P., Hembree, A., \& Park, H. (2020). Open peer review: promoting transparency in open science. Scientometrics, 125. doi: doi: 10.1007/s11192-020-03488-4.

Como citar esta entrevista (APA):

Pedri, P. \& Araújo, R. F. (2021). Revisão por pares aberta. AtoZ: novas práticas em informação e conhecimento, 10(1), VI - IX. Recuperado de: http:// dx.doi.org/10.5380/atoz.v10i1.78747 